\title{
PENINGKATAN PENGETAHUAN REMAJA TENTANG PERILAKU SEKSUAL SETELAH PENDIDIKAN SEKS DAN DAMPAKNYA, TERNATE, INDONESIA
}

\author{
Damir Umanailo, Muhlisa \\ (Prodi D-III Keperawatan, Jurusan Keperawatan, Poltekkes Kemenkes Ternate)
}

\begin{abstract}
In North Maluku, the death rate due to AIDS specifically Ternate is in the first place with the number of deaths 10 people from 9 existing urban districts, in the second place with the highest death rate is in North Halmahhera district with a total of 7 deaths, in third place deaths due to AIDS is West Halmahera district with a total death toll of 5 people. The purpose of this study was to determine the effect of sex education on adolescent knowledge about sexual behavior. This study uses a Pre-Experimental method, with the design of the OneGroup Pre-Post Test. The results showed that before being given sex education $38.6 \%$ of students had sufficient knowledge and students who had a less knowledge were $35 \%$ and those who had good knowledge were only $26.4 \%$ of the total students. whereas after being given sex education, the results showed that students who had good knowledge drastically increased to $81.4 \%$ and students who had less knowledge were only $0.7 \%$ while students who had sufficient knowledge were only $17.9 \%$. The Wilcoxon signed-rank test statistic test shows that $P=0.000$. In Conclusion, there is an effect of providing sex education on increasing adolescent knowledge to sexual behavior. Hoped, in the future related parties can improve the quality and quantity of sex education in adolescents.
\end{abstract}

Keywords: Sexual Behavior; Knowledge; Sex education

\begin{abstract}
Abstrak
Di Maluku Utara angka kematian akibat AIDS di Ternate menempati urutan pertama dengan jumlah kematian sebanyak 10 orang dari 9 kelurahan yang ada, di urutan kedua dengan angka kematian tertinggi ada di Kabupaten Halmahhera Utara dengan jumlah kematian. Dari 7 kematian, urutan ketiga kematian akibat AIDS adalah Kabupaten Halmahera Barat dengan jumlah korban meninggal 5 orang. Tujuan penelitian ini adalah untuk mengetahui pengaruh pendidikan seks terhadap pengetahuan remaja tentang perilaku seksual. Penelitian ini menggunakan metode Pre-Eksperimental, dengan rancangan One-Group Pre-Post Test, yaitu jenis penelitian yang mengungkap hubungan sebab akibat dengan melibatkan satu kelompok subjek. Dimana kelompok subjek diamati sebelum intervensi dilakukan, kemudian diamati kembali setelah intervensi. Hasil penelitian menunjukkan bahwa sebelum diberikan pendidikan seks sebanyak 38,6\% siswa memiliki pengetahuan cukup dan siswa yang memiliki pengetahuan kurang sebanyak 35\% dan yang memiliki pengetahuan baik hanya $26,4 \%$ dari total siswa. Sedangkan setelah diberikan pendidikan seks, hasil penelitian menunjukkan bahwa siswa yang memiliki pengetahuan baik meningkat drastis menjadi $81,4 \%$ dan siswa yang memiliki pengetahuan kurang hanya 0,7\% sedangkan siswa yang memiliki pengetahuan cukup hanya 17,9\%. Uji statistik uji peringkat bertanda Wilcoxon menunjukkan bahwa $P=0,000$. Kesimpulannya adalah terdapat dampak pemberian Pendidikan seks terhadap peningkatan pengetahuan tentang perilaku seksual pada remaja. Diharapkan kedepannya pihak terkait dapat meningkatkan kualitas dan kuantitas Pendidikan seks pada remaja.
\end{abstract}

Kata Kunci : Perilaku Seksual; Pengetahuan; Pendidikan Seks

Penerbit: Poltekkes Kemenkes Padang, http://jurnal.poltekkespadang.ac.id/ojs/index.php/jsm 


\section{PENDAHULUAN}

Perubahan perilaku remaja mengakibatkan remaja semakin rentan terhadap penyakit, terutama yang berkaitan dengan kesehatan reproduksi dan seksual, termasuk meningkatnya ancaman infeksi menular seksual terhadap HIV / AIDS. Organisasi Kesehatan Dunia ${ }^{1}$ menyatakan bahwa setiap tahun terdapat 132 juta kasus baru infeksi menular seksual, sebagian besar pada usia 15-27 tahun. Sejumlah besar remaja di seluruh dunia aktif secara seksual dan dari usia pertengahan hingga akhir remaja proporsi ini terus meningkat. ${ }^{2}$ Perilaku seksual remaja sangat bervariasi antarwilayah; di sub-Sahara Afrika, Asia, dan Asia Tengah lebih banyak anak perempuan yang aktif secara seksual daripada anak laki-laki dan di Amerika Latin dan Karibia lebih banyak anak laki-laki yang aktif secara seksual daripada anak perempuan .2

Seksualitas terus menjadi bidang yang membutuhkan intervensi segera di banyak negara. Perkembangan dalam hal kesehatan seksual dan reproduksi telah diamati dalam beberapa tahun terakhir di Portugis muda, tetapi tidak semua klaim perilaku seksual preventif dan kurangnya perilaku seksual preventif dapat menimbulkan konsekuensi serius dalam hal kesehatan masyarakat. ${ }^{3}$ Beberapa faktor terkait dengan kehamilan pada remaja. Pernikahan terlambat ${ }^{4}$, kurangnya dukungan sosial dan ekonomi ${ }^{4},{ }^{5}$. Rasa ingin tahu dan tekanan teman sebaya ${ }^{6},{ }^{7}$, pendidikan seks yang buruk ${ }^{8}$, pendidikan seks yang tidak memadai ${ }^{9}$ dan tidak profesionalisme penyedia layanan kesehatan untuk kontrasepsi remaja ${ }^{7}$. Apalagi kebutuhan alat kontrasepsi remaja yang belum terpenuhi dan mitos tentang efek samping kontrasepsi ${ }^{10}$ kembali mengurangi kontrasepsi. Sikap berisiko rendah, keterampilan remaja yang buruk dalam menghadapi pilihan seks yang aman ${ }^{11}$ dan debut seks dini cenderung mendorong kehamilan remaja. Setiap pelajaran pendidikan seks dini harus menjawab faktor-faktor di atas.

Pendidikan seks berdasarkan pantangan mendorong seks ditunda sampai pernikahan dan pengajaran kontrasepsi dibatasi pada efek negatifnya. Sebagian besar siswa terlibat dalam perilaku seksual berisiko, seperti narkoba atau alkohol, ${ }^{12}$ berhubungan seks dengan banyak pasangan dan kasual ${ }^{13}$ dan tidak konsisten menggunakan kondom. ${ }^{3}$ Ada 8,06\% remaja laki-laki pernah melakukan hubungan seks pranikah dan $4,17 \%$ perempuan berusia di bawah 18 tahun. Angka Kesuburan Berdasarkan Usia (ASFR) kelompok usia 15-19 tahun pada umumnya 40,1\% per 1000 kelahiran. Data untuk wanita usia 10-54 tahun, 2,6\% menikah pertama kali pada usia kurang dari 15 tahun dan 23,9\% menikah pada usia 15-19 tahun. Di Indonesia terdapat 4.555 penderita AIDS pada tahun 2017 dan 33.660 penderita HIV pada tahun 2017. Pada kasus kencing nanah berdasarkan Laporan Survei Terpadu Biologi dan Perilaku Kementerian Kesehatan RI, terdapat 179\% dan 44\% sifilis.

Di Maluku Utara Angka Kawin Dini Di Bawah 18 Tahun Adalah 10\%, Dan Untuk Angka Kesuburan Berdasarkan Umur (Asfr) Kelompok Umur 15-19 Tahun Sebanyak 62\% Per 
1000 Kelahiran Dimana Maluku Utara Termasuk Sebagai Angka Kesuburan Berdasarkan Umur (Asfr) Tertinggi Di Indonesia Yang Berada Pada Posisi Ke-3.Tahun 2018, Ada 1.109 Penderita HIV / Aids di Maluku Utara Berdasarkan Data Komisi Perlindungan Anak Indonesia. Di Maluku Utara Angka Kematian Akibat Aids di Kota ternate menempati urutan pertama dengan jumlah kematian sebanyak 10 orang dari 9 kabupaten kota yang ada, di urutan kedua dengan angka kematian tertinggi berada di kabupaten halmahhera utara dengan total kematian sebnanyak 7 orang, di urutan ketiga dengan angka kematian akibat aids adalah kabupaten Halmahera barat dengan total angka kematian sebanyak 5 orang ${ }^{14}$. Sedangkan untuk Kota Ternate Sendiri, Data Yang Didapat dari Dinas Kesehatan Kota Ternate untuk Infeksi Menular Seksual Tahun 2017 Tercatat sebanyak 781 Penderita. Tahun 2018 Menurun Menjadi 318 Penderita dan Tahun 2019 Periode Januari Sampai April Ada 101 Penderita Angka Ini Bisa Meningkat atau Menurun di Akhir Tahun.

Penelitian dilakukan di Kota Ternate, Maluku Utara. dimana sebanyak 8,06\% remaja laki-laki melakukan hubungan seks pranikah dan 4,17\% perempuan berusia di bawah 18 tahun. Berdasarkan SUPAS 2015, Angka Kesuburan Spesifik Usia (ASFR) kelompok usia 15-19 tahun secara umum adalah 40,1\% per 1000 kelahiran. Data untuk wanita usia 10-54 tahun, 2,6\% menikah pertama kali pada usia kurang dari 15 tahun dan 23,9\% menikah pada usia 15-19 tahun. Di Indonesia terdapat 4.555 penderita AIDS pada tahun 2017 dan 33.660 penderita HIV pada tahun 2017. Berdasarkan Data dan Kasus Yang diatas, Peneliti Merumuskan Studi Bertajuk Peningkatan Pengetahuan Remaja tentang Perilaku Seksual Setelah Pendidikan Seks, Ternate, Indonesia.

\section{METODE PENELITIAN}

Jenis penelitian yang digunakan adalah Pre-Eksperimental, dengan rancangan OneGroup Pre-Post Test, yaitu jenis penelitian yang mengungkap hubungan sebab akibat dengan melibatkan satu kelompok subjek. Dimana kelompok subjek diamati sebelum intervensi dilakukan, kemudian diamati kembali setelah intervensi. Kriterian inklusi pada penelitian ini adalah sampel berusia 14-19 tahun dan sedang dalam masa sekolah. Kuesioner dibuat dalam bahasa Inggris dan dikelola dalam bahasa Inggris dan bahasa daerah (Indonesia). Siswa diwawancarai dan tanggapan mereka dilaporkan pada survei kertas yang kemudian ditempatkan dalam database komputer. Murid diwawancarai pada awal sebelum dimulainya intervensi pada Sep 2019.

Setelah intervensi tiga bulan selesai, murid diwawancarai lagi pada Desember 2019. Sampel dalam penelitian ini berjumlah 114 orang, metode pemilihan sampel menggunakan non-probability sampling dengan purposive sampling menggunakan pengacakan menjadi kelompok dan dibagi menjadi dua kelompok yaitu kelompok intervensi dan kelompok kontrol. Intervensi dilakukan selama 3 bulan, mulai September hingga Desember dengan 
memberikan materi ajar pendidikan seks remaja yang terbagi dalam beberapa tahap agar diperoleh hasil yang maksimal dan berdasarkan materi standar yang disepakati oleh asosiasi perawat Indonesia.

Data dimasukkan ke SPSS versi 24. Karakteristik peserta dasar antara kelompok intervensi dan kontrol dan variabel sosiodemografi ditentukan dengan menggunakan statistik deskriptif. skor domain dibandingkan antara kelompok intervensi dan kontrol. Data yang telah dimasukkan kemudian diuji statistik dengan menggunakan uji peringkat bertanda Wilcoxon. Untuk mengetahui pengaruh pemberian pendidikan seks terhadap peningkatan pengetahuan remaja.

\section{HASIL PENELITIAN}

Analisis univariat dalam penelitian ini bertujuan untuk melihat distribusi frekuensi karakteristik responden yang meliputi umur, jenis kelamin, dan frekuensi distribusi variabel bebas yaitu Pendidikan Kesehatan Reproduksi dan variabel terikat yaitu Tingkat Pengetahuan Remaja tentang Perilaku Seksual. Tabel berikut menjelaskan secara mendalam karakteristik narasumber.

Tabel 1: Distribusi Frekuensi dan Persentase Usia Responden

\begin{tabular}{ccc}
\hline Usia & Frekuensi & Persentase \\
\hline 13 & 1 & $0,7 \%$ \\
\hline 14 & 12 & $8,6 \%$ \\
\hline 15 & 110 & $78,6 \%$ \\
\hline 16 & 17 & $12,1 \%$ \\
\hline Total & 140 & $100 \%$ \\
\hline
\end{tabular}

Berdasarkan tabel 1 karakteristik umur responden terbanyak adalah berumur 15 tahun sebanyak 110 responden (78,6\%) dan umur responden paling rendah berumur 13 tahun yaitu 1 responden (7\%).

Tabel 2: Distribusi Frekuensi dan Persentase Jenis Kelamin Responden

\begin{tabular}{ccc}
\hline Jenis Kelamin & Frekuensi & Persentase \\
\hline Pria & 61 & $43,6 \%$ \\
\hline Perempuan & 79 & $56,4 \%$ \\
\hline Total & 140 & $100 \%$ \\
\hline
\end{tabular}

Berdasarkan tabel 2, karakteristik jenis kelamin responden terbanyak adalah perempuan, 79 responden (56,4\%), dan laki-laki sebanyak 61 responden (43,6\%). 
Tabel 3: Distribusi Frekuensi dan Persentase Pengetahuan Remaja Pre-Tes tentang Perilaku Seksual

\begin{tabular}{ccc}
\hline Pra Tes & Frekuensi & Persentase \\
\hline Baik & 37 & $26,4 \%$ \\
\hline Cukup & 54 & $38,6 \%$ \\
\hline Kurang & 49 & $35 \%$ \\
\hline Total & 140 & $100 \%$ \\
\hline
\end{tabular}

Berdasarkan tabel 3 dapat diketahui bahwa pengetahuan remaja tentang perilaku seksual dibedakan menjadi 3 kategori, Baik, Cukup, dan Kurang. Data prates yang diperoleh adalah pengetahuan baik sebanyak 37 responden (26,4\%), pengetahuan cukup sebanyak 54 responden (38,6\%), dan yang kurang pengetahuan sebanyak 49 responden (35\%).

Tabel 4: Distribusi Frekuensi dan Persentase Pengetahuan Remaja Pasca Tes tentang Perilaku Seksual

\begin{tabular}{ccc}
\hline Pasca Tes & Frekuensi & Persentase \\
\hline Baik & 114 & $81,4 \%$ \\
\hline Cukup & 25 & $17,9 \%$ \\
\hline Kurang & 1 & $0,7 \%$ \\
\hline Total & 140 & $100 \%$ \\
\hline
\end{tabular}

Berdasarkan tabel 3 dapat diketahui bahwa pengetahuan remaja tentang perilaku seksual dibedakan menjadi 3 kategori, Baik, Cukup, dan Kurang. Data pre-test yang diperoleh adalah pengetahuan baik 114 responden (81,4\%), pengetahuan cukup sebanyak 25 responden (17,9\%), dan yang kurang pengetahuan sebanyak 1 responden $(0,7 \%)$.

Tabel 5. Pengaruh Pendidikan Seks terhadap Tingkat Pengetahuan Remaja tentang Perilaku Seksual

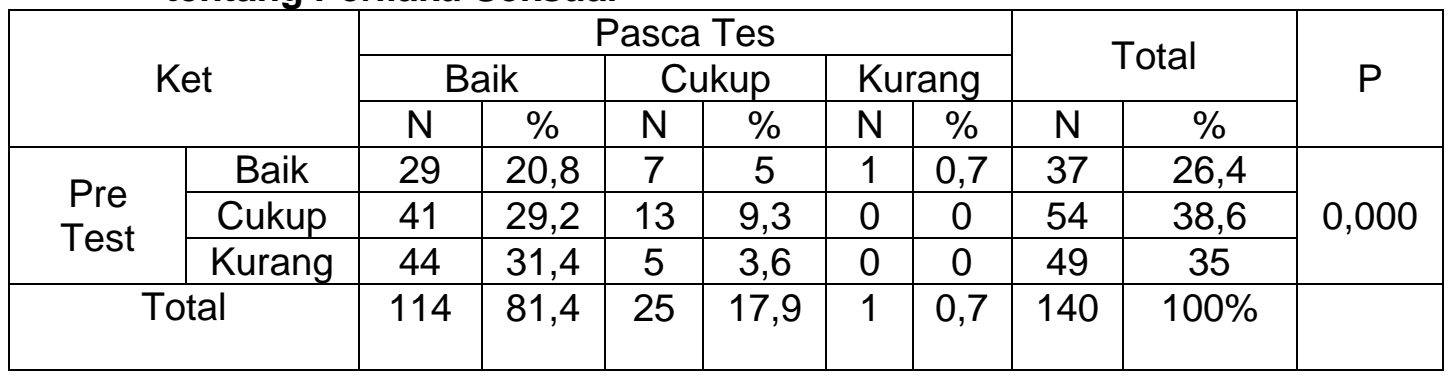

Berdasarkan hasil uji statistik Wilcoxon signed-rank test diperoleh nilai $\mathrm{P}$ (approx. Significant) $=0,000$ dimana $P$-value $<0,05$ yang artinya terdapat pengaruh pemberian pendidikan seks terhadap tingkat pengetahuan remaja. tentang perilaku seksual. 


\section{PEMBAHASAN}

Temuan dalam penelitian ini menunjukkan bahwa mayoritas responden remaja sekolah tidak memiliki pengetahuan tentang seks dan seksualitas akibat kurangnya Pendidikan seks di sekolah. Sebelum diberikan pendidikan seks, sebagian besar pengetahuan siswa berada pada kategori cukup yaitu 54 responden. Dan pada saat post test sebagian besar pengetahuan siswa berada pada kategori baik yaitu 114 responden. Penelitian ini juga sejalan dengan penelitian yang dilakukan oleh ${ }^{15}$ yang mengatakan bahwa Sebuah Program pendidikan seks komprehensif yang dipandu oleh HBM, mengurangi aktivitas seksual remaja dalam jangka pendek dan meningkatkan pengetahuan mereka tentang pencegahan kehamilan. Dari hasil penelitian di atas diketahui bahwa pemberian pendidikan seks dapat memberikan pengetahuan yang baik khususnya pengetahuan tentang perilaku seksual, karena pendidikan kesehatan merupakan intervensi yang terstruktur dan sangat baik. Untuk para orangtua, pendidik, konselor serta pemerhati anak muda, para anak muda spesialnya siswa/ i masih sangat butuh menemukan pembelajaran intim. Untuk anak muda, butuh membentengi diri supaya tidak melaksanakan sikap intim yang menyimpang serta tidak sehat dengan menguasai determinannya. ${ }^{16}$

Pendidikan kesehatan merupakan proses terstruktur sebagai bentuk utama dari intervensi perilaku yang bertujuan untuk mempengaruhi sikap, pengetahuan, dan perilaku individu, kelompok, dan masyarakat sehingga dilakukan upaya peningkatan kesehatan. Pendidikan seks berbasis sekolah memberikan pendekatan formal untuk mensosialisasikan remaja dalam perilaku yang mencerminkan norma dan nilai seksual dari kelompok yang paling berpengaruh dalam masyarakat tertentu. ${ }^{16}$ Pendidikan seksual dapat memberikan dampak yang lebih besar pada pengetahuan dan sikap mereka dengan meningkatkan pengetahuan seksual siswa dan waktu yang lama serta kegiatan tambahan untuk pendidikan seks. Hal ini telah mempengaruhi pengembangan pendekatan pengajaran pendidikan seks karena temuan-temuan penelitian digunakan untuk memberi nasihat kepada Negara ${ }^{17}$ Banyak manfaat dari pendidikan awal seks seperti yang dikemukakan oleh ${ }^{18}$ menyatakan Menerima pendidikan seks formal sebelum hubungan seksual pertama dikaitkan dengan penundaan inisiasi seksual dan peningkatan penggunaan kontrasepsi pada hubungan seksual pertama. Menerima pendidikan seks sebelum hubungan seksual pertama dapat membantu menjangkau orang yang sehat.

Studi tersebut menyimpulkan bahwa pendidikan seks saja tidak boleh sepenuhnya dipahami sebagai strategi untuk mengurangi risiko. Melainkan harus dilihat sebagai tindakan multi-segi, dengan efek yang bermanfaat atau tidak membuahkan hasil karena interaksi sosio-kultural antara tindakan tersebut dan kemanjurannya, yang seringkali membingungkan. Misalnya, meyakinkan remaja dengan persepsi negatif tentang penggunaan kondom dibandingkan kenikmatan seksual yang terganggu merupakan tugas 
yang berat, karena masalahnya sendiri bersifat subjektif dan, pada tingkat yang lebih besar, kemauan.$^{19}$ Ada pergeseran lokus risiko dari satu individu ke individu lain dalam masyarakat besar, dengan remaja kehilangan kerentanan mereka. Misalnya, remaja yang memiliki dua pasangan seksual merasa lebih aman dibandingkan remaja yang memiliki tiga pasangan seksual atau lebih. Pemikiran seperti itu mengurangi kerentanan mereka terhadap segala jenis risiko yang mungkin mereka hadapi dalam situasi seperti HIV / AIDS dan kehamilan. Penelitian tersebut sekarang melakukan aktivitas seksual berisiko di mana para siswa yakin hal ini tidak akan membahayakan kehidupan seks mereka, kecuali kehidupan rekan mereka, meskipun mereka telah mengetahui tentang HIV / AIDS melalui pendidikan seks.$^{20}$

Klaim untuk menghargai netralitas adalah kelemahan utama dalam pendidikan seks yang didominasi oleh pengetahuan. Konsepnya adalah temuan dan kesimpulannya tidak ditentukan oleh nilai budaya apa pun, tetapi oleh kebenaran ilmiah dan bukti obyektif. Masalah seksualitas tidak dapat dengan sengaja diabaikan dalam studi ilmiah meskipun bahasa moralitas tradisional harus direvisi secara radikal.. Literasi seksual sejati membutuhkan penulisan ulang seksualitas, penulisan ulang korpus Mundi. Itulah tugas kritikus seks: mengubah dunia menjadi karya seni objektif yang mengubah dunia. Ini adalah tugas puisi: menggunakan huruf secara kreatif, bukan untuk meningkatkan wacana nonotentik yang mengabadikan masalah dengan berbicara murni. ${ }^{20}$.

Kajian empiris tentang seksualitas tidaklah penting, karena seksualitas sudah tertanam dalam kepercayaan budaya sebagai topik kajian. Seksualitas bukanlah fakta ilmiah yang pasti. Ini terkait dengan sistem sosial budaya yang dalam. Lebih jauh, seksualitas bukanlah, seperti yang sering diartikan, kemampuan otonom, tekanan teman sebaya, norma budaya, kesetaraan gender atau bahkan beban keuangan, yang mempengaruhi seksualitas. ${ }^{21}$. Oleh karena itu, ilmu seksualitas biasanya berfokus pada memengaruhi keyakinan, seperti upaya mengidentifikasi aktivitas seksual yang 'benar'. Netralitas tertinggi yang dapat ditegaskan oleh seorang ilmuwan mengenai seksualitas oleh karena itu bukanlah netralitas kepentingan, tetapi preferensi atas nilai-nilai tersebut di atas orang lain. Hal ini pada gilirannya dicapai dengan medikalisasi atau mengubah pendidikan seks menjadi pendidikan kesehatan reproduksi, yang mengajarkan atau memprioritaskan praktik seksual yang lebih sehat daripada masalah seksual lainnya.

Agar berhasil, pendidikan seks harus dipahami dan dilibatkan dalam budaya. Hal ini dimungkinkan dengan "menemukan berbagai sumber yang digunakan kaum muda untuk menemukan berbagai jenis informasi seksual dan bagaimana sumber dan jenis informasi tersebut berinteraksi satu sama lain". ${ }^{21}$. Argumen ini adalah bahwa pendidikan seks tidak dapat mengubah budaya yang tidak dapat dipahami. Pendidik seks tidak dapat mengetahui apakah akan mengutuk suatu komunitas atau tidak tanpa analisis yang cermat terhadap 
budaya dominan dalam pengertian di mana komunitas tersebut beroperasi. Bahkan budaya itu sendiri dapat membantu mendukung praktik seksual yang lebih baik dan mempromosikannya. Sumber daya ini harus digunakan lebih dari sekadar membuat sumber daya baru, dan cara untuk membuatnya dapat dipahami dalam konteks budaya tertentu lebih bermanfaat.

Meskipun terdapat informasi yang bertentangan dan praktik terbaik, penelitian telah menunjukkan kendala yang signifikan dalam perubahan perilaku. Misalnya faktor sosial ekonomi dan budaya seperti kebutuhan finansial remaja putri dan tekanan finansial pada orang tua mereka yang mengakibatkan pengasuhan dan tanggung jawab yang tepat terancam. Karena ada kebutuhan yang sangat besar akan uang, tekanan teman sebaya membuat "kehamilan di usia remaja, aborsi, dan pernikahan dini" sangat sulit untuk ditahan ${ }^{22}$. Sekarang kita tahu bahwa apapun agendanya, pendekatan ilmiah murni tidak dapat mencapai hasil jika pendidikan seks dipertimbangkan. Ketika program mengubah perilaku, faktor budaya harus didiskusikan yang memicu perilaku negatif. Pendidik seksual perlu menyadari bahwa perbaikan bermanfaat dalam perilaku seksual tidak dapat dikaitkan dengan pengetahuan ilmiah saja karena terkadang "bukti ilmiah tidak sejalan dengan aktivitas sehari-hari.

Ketika kesadaran kesehatan menjadi agenda lebih, pendidik seks harus mampu mengkomunikasikan pesan mereka melalui dukungan budaya, terutama dengan menggunakan bahasa yang tepat untuk mencegah perlawanan yang tidak perlu. Dalam sejarah, ilmuwan seringkali menghadapi risiko di masyarakat bukan karena mereka percaya kebohongan tetapi karena mereka juga mengabaikan masyarakat sebagai alat untuk mengkomunikasikan realitas. Salah satu alasan utama mengapa pendekatan terhadap seksualitas berdasarkan informasi selalu disukai adalah karena pendekatan itu cenderung lebih baik dalam membela kesalahan dan asumsi yang salah. Di sisi lain, sains, seperti budaya, bukanlah bukti kesalahan atau sistem pengetahuan yang sempurna, tetapi juga merupakan sistem yang terkadang menciptakan analogi dan asumsi.

Pada generasi lain, beberapa prinsip yang dianggap kebenaran ilmiah terbukti salah atau tidak melengkapi posisi atau evaluasi terhadap realitas. Mungkin salah satu komentarnya adalah bahwa pengetahuan atau konsep ilmiah tidak sesuai untuk mereka yang memperjuangkan dominasi kerangka pengetahuan / ilmiah / medis dalam pendidikan seks. Entitas budaya dengan beragam norma dan motif budaya diapropriasi dengan berbagai cara. Karena keniscayaan budaya bahkan dalam konteks ilmiah murni, Saya tidak ingin menyebutkan posisi mereka dalam pengetahuan atau pendidikan seksual ilmiah. Tinggi realistik yang bisa dicapai adalah keunggulan pengetahuan tentang nilai-nilai atau budaya yang terpinggirkan. 


\section{SIMPULAN DAN SARAN}

Terdapat dampak pemberian Pendidikan seks terhadap peningkatan pengetahuan tentang perilaku seksual pada remaja. Diharapkan kedepannya pihak terkait dapat meningkatkan kualitas dan kuantitas Pendidikan seks pada remaja.

\section{DAFTAR PUSTAKA}

1. World Health Organization, UNICEF, UNAIDS. Global Update on HIV Teratment 2013 : Results, Impact and Opportunities. WHO Library Cataloguing-in-Publication Data Global. 2013. 7 hal.

2. Chandra-mouli V, Mccarraher DR, Phillips SJ, Williamson NE. Contraception for adolescents: Social, clinical and service delivery considerations Contraception for adolescents in low and middle income countries : needs, barriers, and access. Reprod Health [Internet]. 2014;11(1):1-8. Tersedia pada: https://reproductive-healthjournal.biomedcentral.com/track/pdf/10.1186/1742-4755-11-1 ?site=reproductive-healthjournal.biomedcentral.com

3. Reis M, Ramiro L, de Matos MG, Diniz JA. Determinants Influencing Male Condom Use Among University Students in Portugal. Int J Sex Heal. 2013;25(2):115-27.

4. Ahorlu CK, Pfeiffer C, Obrist B. Socio-cultural and economic factors influencing adolescents' resilience against the threat of teenage pregnancy: A cross-sectional survey in Accra, Ghana Adolescent Health. Reprod Health [Internet]. 2015;12(1):1-11. Tersedia pada: http://dx.doi.org/10.1186/s12978-015-0113-9

5. Kumi-Kyereme A, Awusabo-Asare K, Darteh EK ofuo. M. Attitudes of gatekeepers towards adolescent sexual and reproductive health in Ghana. Afr J Reprod Health. 2014;18(3):142-53.

6. Yidana A, Ziblim S-D, Azongo TB, Abass YI. Socio-Cultural Determinants of Contraceptives Use Among Adolescents in Northern Ghana. Public Heal Res [Internet]. 2015;5(4):83-9. Tersedia pada: Adolescent in both rural and urban areas in developing nations are often underserved by family planning service providers. This limits the knowledge level of young men and women about contraceptive methods. The purpose of this study was to examine what de

7. Mushwana L, Monareng L, Richter S, Muller H. Factors influencing the adolescent pregnancy rate in the Greater Giyani Municipality, Limpopo Province - South Africa. Int J Africa Nurs Sci [Internet]. 2015;2(February):10-8. Tersedia pada: http://dx.doi.org/10.1016/j.ijans.2015.01.001

8. Kaufman MR, Smelyanskaya M, Van Lith LM, Mallalieu EC, Waxman A, Hatzhold K, et al. Adolescent sexual and reproductive health services and implications for the provision 
of voluntary medical male circumcision: Results of a systematic literature review. PLoS One. 2016;11(3):1-23.

9. Atuyambe LM, Kibira SPS, Bukenya J, Muhumuza C, Apolot RR, Mulogo E. Understanding sexual and reproductive health needs of adolescents: Evidence from a formative evaluation in Wakiso district, Uganda Adolescent Health. Reprod Health [Internet]. 2015;12(1):1-10. Tersedia pada: ???

10. Chandra-Mouli V, Camacho AV, Michaud PA. WHO guidelines on preventing early pregnancy and poor reproductive outcomes among adolescents in developing countries. J Adolesc Heal [Internet]. 2013;52(5):517-22. Tersedia pada: http://dx.doi.org/10.1016/j.jadohealth.2013.03.002

11. Krugu JK, Mevissen FEF, Prinsen A, Ruiter RAC. Who's that girl? A qualitative analysis of adolescent girls' views on factors associated with teenage pregnancies in Bolgatanga, Ghana. Reprod Health [Internet]. 2016;13(1):1-12. Tersedia pada: http://dx.doi.org/10.1186/s12978-016-0161-9

12. Ghandour LA, Mouhanna F, Yasmine R, El Kak F. Factors associated with alcohol and/or drug use at sexual debut among sexually active university students: Crosssectional findings from Lebanon. BMC Public Health. 2014;14(1):1-10.

13. Garcia JR, Reiber C, Massey SG, Merriwether AM. Sexual hookup culture: A review. Rev Gen Psychol. 2012;16(2):161-76.

14. Dinas Kesehatan Maluku Utara. PROFIL KESEHATAN PROVINSI MALUKU UTARA TAHUN 2012. 2012.

15. Yakubu I, Garmaroudi G, Sadeghi R, Tol A, Yekaninejad MS, Yidana A. Assessing the impact of an educational intervention program on sexual abstinence based on the health belief model amongst adolescent girls in Northern Ghana, a cluster randomised control trial. Reprod Health. 2019;16(1):1-12.

16. Haryadi H. Perilaku Seksual Siswa SMA Negeri Di Kota Tanjungpinang dan Hubungannnya Dengan Perkembangan Biologis. J Sehat Mandiri. 2017;12(2):1-9.

17. Gardner EA. Abstinence-Only Sex Education: College Students' Evaluations and Responses. Am J Sex Educ. 2015;10(2):125-39.

18. Leung $H$, Shek DTL, Leung E, Shek EYW. Development of contextually-relevant sexuality education: Lessons from a comprehensive review of adolescent sexuality education across cultures. Int J Environ Res Public Health. 2019;16(4):1-24.

19. Reis M, Ramiro L, De Matos MG, Diniz JA. The effects of sex education in promoting sexual and reproductive health in Portuguese university students. Procedia - Soc Behav Sci [Internet]. 2011;29:477-85. Tersedia pada: http://dx.doi.org/10.1016/j.sbspro.2011.11.266 
20. Rashid S, Mwale M. The Effects of Sex Education on the Risky Sexual Behaviour of School Going Adolescents: A Case Study of Mbenjere Secondary, Ntaja and Nsanama Community Day Secondary Schools. Psychol Dev Soc J. 2016;28(1):126-38.

21. Stephenson R, Winter A, Elfstrom M. Community environments shaping transactional sex among sexually active men in Malawi, Nigeria, and Tanzania. AIDS Care - Psychol Socio-Medical Asp AIDS/HIV. 2013;25(6):784-92.

22. McKee A, Watson AF, Dore J. 'It's all scientific to me': focus group insights into why young people do not apply safe-sex knowledge. Sex Educ [Internet]. 2014;14(6):65265. Tersedia pada: http://dx.doi.org/10.1080/14681811.2014.917622 